\title{
Flora das cangas da Serra dos Carajás, Pará, Brasil: Aristolochiaceae
}

\author{
Flora of the canga of the Serra dos Carajás, Pará, Brazil: Aristolochiaceae
}

\author{
Ivan Silva Abreu ${ }^{1}$, Nara Furtado de Oliveira Mota ${ }^{1,2}$ \& Ana Maria Giulietti ${ }^{1,3}$
}

\begin{abstract}
Resumo
É apresentado o tratamento florístico das espécies de Aristolochiaceae que ocorrem associadas às cangas da Serra dos Carajás, no estado do Pará, Brasil. Um gênero e três espécies foram registradas: Aristolochia mossii de distribuição amazônica e periamazônica, A. rugosa de distribuição no Cerrado e na Amazônia e Aristolochia aff. disticha ainda com identificação incerta. São incluídas chave de identificação, descrições, ilustrações, fotografias em campo e comentários sobre as espécies.

Palavras-chave: Amazônia, Floresta Nacional de Carajás, flora, taxonomia.
\end{abstract}

\begin{abstract}
We present the floristic treatment for the species of Aristolochiaceae from the canga of the Serra dos Carajás, state of Pará, Brazil. One genus and three species are recorded: Aristolochia mossii with Amazonian and periamazonic distribution, A. rugosa with distribution in the Cerrado and Amazonia, and Aristolochia aff. disticha with uncertain identification. An identification key, descriptions, illustrations, photos, and comments are also provided.
\end{abstract}

Key words: Amazonia, National Forest of Carajás, flora, taxonomy.

\section{Aristolochiaceae}

Aristolochiaceae Juss. pertence as dicotiledôneas basais (Magnoliidae), incluída em Piperales juntamente com Saururaceae e Piperaceae (Massoni et al. 2014). Segundo Huber (1993), a família incluía Aristolochiaceae subf. Asaroideae com Saruma Oliv. com uma espécie da China, e Asarum L. com cerca de 70 espécies de áreas subtropicais e temperadas, e Aristolochiaceae subf. Aristolochioideae com dez gêneros. Com estudos taxonômicos e morfológicos, são reconhecidos atualmente nessa subfamília os gêneros: Thottea Rottb. com 25 espécies asiáticas, incluindo Asiphonia piperoides Griff., e Aristolochia L. que incluiu os outros sete gêneros, e ampliou para mais de 400 o número de suas espécies (Ohi-Toma et al. 2006), além da distribuição geográfica para incluir a Europa, Ásia, África e Américas (Pfeifer 1966; González 1990, 1997; Kelly \& Gonzalez 2003).

Estudos filogenéticos com dados moleculares, modificaram o número e circunscrição dos gêneros de Aristolochiaceae. Qiu et al. (2005) e Neinhuis et al. (2005) incluíram Lactoridaceae (Lactoris Phil.) em Aristolochiaceae, e Nickrent et al. (2002) e Naumann et al. (2013) incluíram Hydnoraceae em Aristolochiaceae. Massoni et al. (2014) ao apresentarem a filogenia das Magnoliidae, consideraram Aristolochiaceae s.l. (incluindo Lactoris Phil. e Hydnora africana Thunb.) como monofilética e irmã do clado formado por Saururaceae e Piperaceae, constituindo as Piperales. Esses trabalhos, sustentaram a delimitação de Aristolochiaceae como proposta na APG IV (2016), e utilizada nesse trabalho.

Aristolochiaceae compreende atualmente seis gêneros e cerca de 560 espécies com distribuição cosmopolita, e com maior diversidade na região tropical. Apresenta morfologia, formas de vida e polinização variadas o que talvez justifica a controversa inclusão de seus gêneros, como discutido anteriormente. São ervas perenes como Asarum e Saruma henryi Oliv., única espécie do gênero; trepadeiras volúveis como em Thottea; arbustos como Lactoris fernandeziana Phil., única espécie do gênero, endêmica do Arquipélago Juan Fernandez, no Chile; holoparasita como Hydnora Thunb., com seis espécies principalmente da África (Bolin et al. 2011) e Prosopanche de Bary com uma espécie da América Central e três da América do Sul (Machado

\footnotetext{
${ }^{1}$ Instituto Tecnológico Vale, R. Boaventura da Silva 955, Nazaré, 66055-090, Belém, PA, Brasil.

${ }^{2}$ Museu Paraense Emilio Goeldi, Campus de Pesquisa, Coord. Botânica, Av. Perimetral 1901, Terra Firme, 66077-830, Belém, PA, Brasil.

${ }^{3}$ Autor para correspondência: ana.giulietti@itv.pq.org
} 
\& Queiroz 2012); ou ervas perenes com estruturas subterrâneas de reserva (xilopódios), trepadeiras ou lianas volúveis ou pequenas arvoretas, como em Aristolochia L. As flores são geralmente isoladas, trímeras, monoclamídeas (Saruma é diclamídea), prefloração valvar, actino ou zigomorfas, estames (3-)6-12 (-30), unidos ou livres, ovário ínfero sincárpico, ou súpero sincárpico ou apocárpico, com ginostêmio ou não e fruto cápsula, folículo ou bacáceo (Griffith 1845; Hoehne 1927, 1942; González 1990, 1997; Barringer 1993; Huber 1993; Nickrent et al. 2002; Shaiju \& Omarakumari 2010; Bolin et al. 2011; Machado \& Queiroz 2012; Stevens 2001, onwards).

No Brasil, Aristolochiaceae inclui os gêneros Prosopanche com P. bonacinai Spegazzini que ocorre no Rio Grande do Sul, Paraguai, Argentina e Bolívia e P. caatingicola R.F.Machado \& L.P.Queiroz das Caatingas da Bahia (Machado \& Queiroz 2012), e Aristolochia encontrada em todos os domínios fitogeográficos (BFG 2015; Flora do Brasil 2020, em construção). Na Serra dos Carajás foram registradas três espécies do gênero Aristolochia, que ocorrem em bordas de mata ou próximas a trilhas e estradas.

\section{Aristolochia L.}

O gênero Aristolochia incluindo cerca de 450 espécies é o maior da família e tem distribuição nas regiões tropicais e subtropicais (Pfeifer 1966; OhiToma et al. 2006). As espécies são caracterizadas principalmente pela morfologia floral, incluindo perianto monoclamídeo, zigomorfo, com sépalas petaloides fusionadas em uma estrutura tubular, na qual destacam-se o tubo inferior (geralmente denominado de utrículo, bojo ou colo), e o tubo superior (geralmente denominado de tubo), que termina nos lábios que margeiam a fauce (também denominado de limbos), androceu e gineceu fusionados em uma estrutura chamada ginostêmio e ovário ínfero (Hoehne 1927, 1942; Abreu 2015). As espécies do gênero apresentam adaptações relacionadas aos mecanismos de polinização por diversos grupos de Dípteros (Sakai 2002; Rulik et al. 2008).

Para o Brasil, são referidas 93 espécies que ocorrem em todas as regiões e estados (BFG 2015; Flora do Brasil 2020, em construção). Nas serras dos Carajás, ocorrem três espécies do gênero.

\section{Chave de identificação das espécies de Aristolochia ocorrentes nas cangas da Serra dos Carajás}

1. Flores reunidas em inflorescências, perianto creme escuro a castanho-claro externamente 1.1. Aristolochia aff. disticha

1'. Flores solitárias, perianto amarelado ou castanho-esverdeado externamente 2

2. Folhas com face abaxial glabra, perianto amarelado com máculas castanhas, lábio superior oblongo, internamente com fímbrias, margem convoluta, ápice cuspidado .......... 1.2. Aristolochia mossi

2'. Folhas com face abaxial pubérula, perianto castanho-esverdeado, lábio superior oval, internamente sem fímbrias e com estrias, margem plana, ápice agudo 1.3. Aristolochia rugosa

1.1. Aristolochia aff. disticha Mast. Fl. bras. 14(2): 110. 1875. Figs. 1a-d; 2f-g Erva ereta passando a trepadeira volúvel, perene; ramos pubérulos, passando a glabrescentes, súber presente; profilos intrapeciolares ausentes. Folhas com pecíolo 2-3 cm compr.; lâmina oval a estreito-oval 7,5-15 × 4,5-8 cm, papirácea, ápice agudo, base lobada, sinus 1,1-2 cm compr., face adaxial glabra, face abaxial pubérula; 5 nervuras a partir da dicotomização das nervuras principais e laterais. Flores em ripídios caulifloros, dísticos, 4-6 cm compr., até 10 flores, brácteas ca. 2 mm compr., cedo caducas, pedicelo (incluindo o ovário) 1,5-4 $\mathrm{cm}$ compr. Perianto externamente creme escuro a bege, glabro; internamente marrom claro com tricomas brancos; tubo inferior oblongoide, ca. 1 $\times 0,9 \mathrm{~cm}$; tubo superior, ca. $3 \mathrm{~cm}$ compr.; lábios superior e inferior quase indistintos, lábio inferior oval, margem revoluta, ápice emarginado; lábio superior lanceolado, internamente marrom escuro, ápice com cauda que cresce durante a maturação da flor. Cápsulas elipsoides, ca. $4 \times 1 \mathrm{~cm}$, pouco rostradas, septos fibrosos. Sementes não vistas.

Material examinado: Canaã dos Carajás, Parque Nacional dos Campos Ferruginosos, Serra do Tarzan, 6020'00"S, 5009'31'W, 721 m, 27.III.2015, fl., P.L. Viana et al. 5667 (MG). Parauapebas, [Marabá], Serra Norte, estrada do N3 em mata de terra firme. 25.III.1985, fr., R.S. Secco et al. 566 (MG).

Material adicional examinado: Aristolochia disticha Mast. BRASIL, PARÁ: Itaituba, Serra do Cachimbo, estrada Santarém-Cuiabá BR 163, km 842 a 850, $09^{\circ} 00^{`} \mathrm{~S}, 54^{\circ} 58^{\prime} \mathrm{W}$, cerrado, solo arenoso, 05.V.1983, infl. velha, M.N. Silva et al. 252 (MG). Identificado por J. Freitas 2017. 


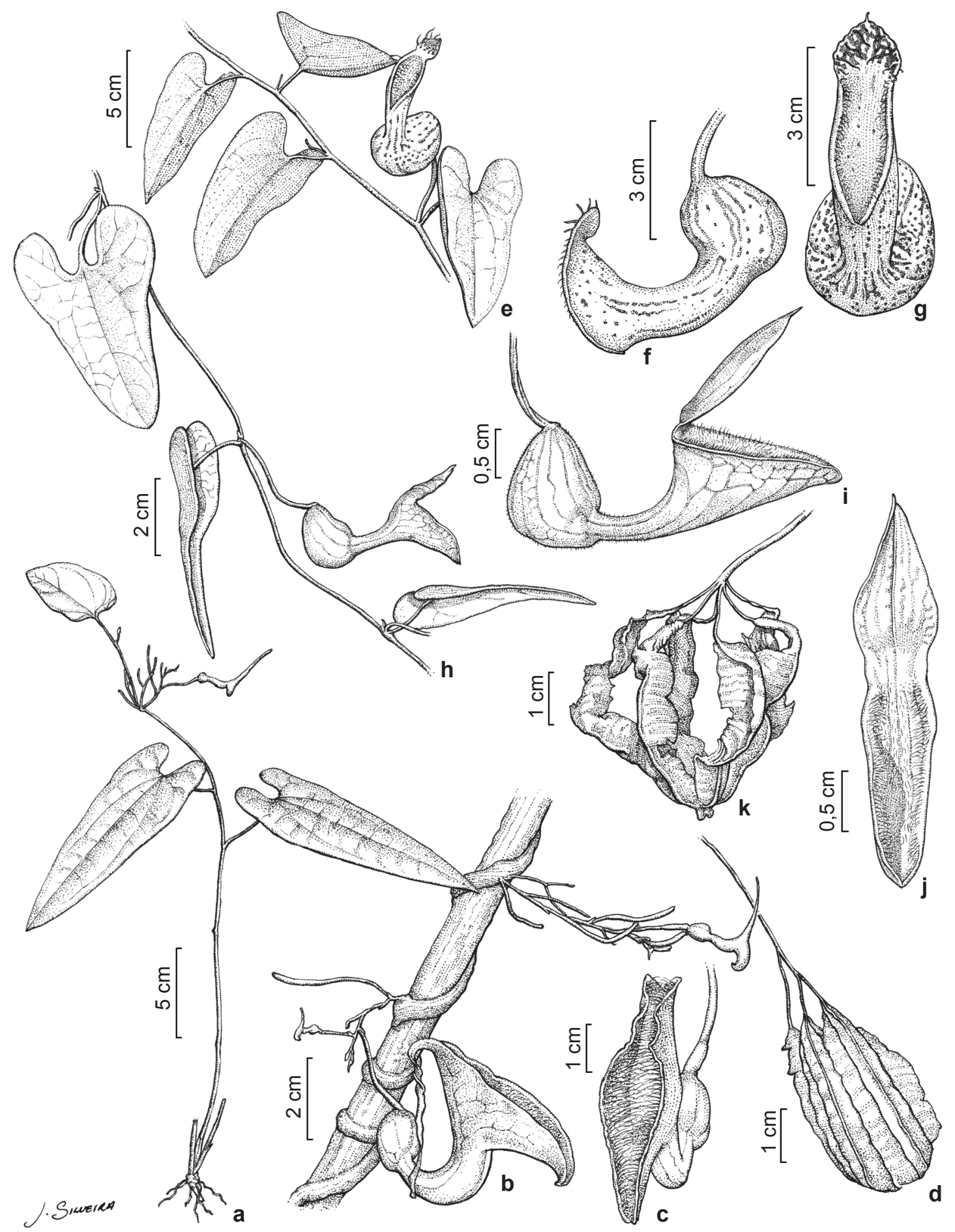

Figura 1- a-d. Aristolochia aff. disticha - a. hábito; b. detalhe do caule preso ao suporte, inflorescência e flor; c. flor mostrando os lábios; d. cápsula não deiscente. e-g. Aristolochia mossii - e. hábito; f. flor em vista lateral; g. flor em vista frontal, mostrando as fímbrias no lábio superior. h-k. Aristolochia rugosa - h. hábito; i. flor em vista lateral; j. lábios superior e inferior em vista frontal; $\mathrm{k}$. cápsula deiscente.

Figure 1 - a-d. Aristolochia aff. disticha - a. habit; b. detail of the stem attached to support, inflorescence and flower; c. flower showing the lips; d. capsula undehisced. e-g. Aristolochia mossii - e. habit; f. flower in lateral view; g. flower in frontal view, showing the fimbria on upper lip. h-k. Aristolochia rugosa-h. habit; i. flower in lateral view; j. upper and lower lips in frontal view; k. dehisced capsule. 
Em Carajás, Aristolochia aff. disticha foi registrada tanto na Floresta Nacional, Serra Norte: N3, como no Parque Nacional dos Campos Ferruginosos, Serra do Tarzan. O espécime coletado na Serra Norte (Secco 566) inclui ramo com folhas e inflorescência em ripídio, dístico, e porta um fruto jovem, sendo referido na etiqueta que se trata de um cipó que se enrola fixamente a arvoretas finas no subosque da mata de terra firme. Diferentemente, os dois espécimes coletados na Serra do Tarzan (Viana et al. 5567) encontram-se no subosque da mata, na estrada para as áreas de canga e bem próximo delas. Um deles é uma erva com até $50 \mathrm{~cm}$ de altura com rizomas castanhoescuros e ramos eretos verdes e folhas ligeiramente discolores com face inferior verde-claro e está portando inflorescência e botões (Fig. 1h), O outro espécime é mais desenvolvido e se mostra com hábito trepador sobre os arbustos do subosque, portando flores em botão, em antese e fruto (Figs. 1i; 2f-g). Esses espécimes associam dois caracteres que em conjunto são raros em Aristolochia, a ausência de profilos axilares (pseudoestípulas segundo Hoehne 1927) e as flores reunidas em ripídios (racemos segundo Hoehne 1927; González et al. 2014).

Usando a chave de Hoehne (1927) a espécie de que mais se aproximam é Aristolochia disticha que foi descrita por Masters (1875) na Flora brasiliensis baseando-se em material coletado por Spruce em Santarém, depositado em Kew e desprovido de flores e frutos. O autor considerou que a inflorescência em racemos com pedicelos em disposição dística era suficiente para reconhecer a espécie como nova. Hoehne (1927) faz descrição e ilustração detalhada da espécie. Gonzalez et al. (2014) fizeram a tipificação da espécie e incluíram A. setulosa A.A.M.Araújo na sua sinonímia. Para os autores a espécie está registrada para a Venezuela, Guiana Francesa, Suriname, Peru, Bolívia e Brasil, onde ocorre na Região Norte (Amazonas e Pará) e Nordeste (Bahia, Paraíba e Rio Grande do Norte).

Os espécimes de Carajás foram comparados com as descrições de Aristolochia disticha constantes em Hoehne (1927) e em Gonzalez et al. (2014) e com o espécime Silva et al. 252 (MG). Esse inclui um ramo com folhas e no envelope uma inflorescência velha do tipo ripídio, dístico, e pedicelos e ovários. Os espécimes de Carajás e Aristolochia disticha compartilham a forma e dimensões das lâminas e pecíolos, comprimento e disposição dos ripídios, brácteas reduzidas e comprimento da cápsula, além da distribuição geográfica. Diferem principalmente pelo hábito, que nas plantas de Carajás podem ser ervas, e por A. disticha apresentar número maior de flores (até 15) na inflorescência, perianto externamente com coloração branco-amarelado com riscas roxas e ausência de calda no lábio superior. A análise de maior número de espécimes é necessário para a correta identificação das plantas de Carajás.

1.2. Aristolochia mossii S. Moore, J. Bot. 53: 7. Tab. 535 f. 2.1915.

Figs. 1e-g; 2a-b

Trepadeira volúvel, perene; ramos glabros, súber ausente; profilos intrapeciolares ausentes. Folhas com pecíolo 1,5-2,5 cm compr.; lâmina oval, 7,7-10,2 × 5-5,8 cm, papirácea, ápice agudo a obtuso, base lobada, sinus 1,2-1,5 cm compr., face adaxial glabra, brilhante quando seca, face abaxial glabra, fosca e mais clara quando seca; 4(-6) nervuras a partir da dicotomização das nervuras principais e laterais. Flores solitárias, pedúnculo (incluindo o ovário) ca. $4 \mathrm{~cm}$ compr., glabro. Perianto externamente amarelado com máculas marrons, glabro; internamente amarelado com tricomas alvos; tubo inferior obovoide ca. 1,5 cm compr.; tubo superior ca. $5 \mathrm{~cm}$ compr.; lábio inferior inconspícuo, margem revoluta, ápice emarginado; lábio superior oblongo, internamente com fímbrias de cor marrom no ápice, margem convoluta, ápice cuspidado. Cápsulas não vistas. Material examinado: Canaã dos Carajás, aceiro próximo ao Rio Parauapebas, $06^{\circ} 28^{\prime} 9,6^{\prime \prime} \mathrm{S}, 50^{\circ} 02^{\prime} 52.7^{\prime}$ 'W, 03.II.2011, fl., L. Tyski 63 (CVRD, HCJS). Parauapebas [Marabá], arredores do acampamento do Rio Azul, Serra dos Carajás, 07.XI.1983, fl., N.A. Rosa et al. 4532 (MG); Serra dos Carajás, barragem de estéril, 26.XII.1988, fl., J.A.A. Bastos 89 (CVRD, HCJS).

Aristolochia mossii foi uma das cinco espécies coletadas pelo Rev. A. Miles Moss nos arredores de Belém em 1914, depositadas no Herbário do British Museum (BM, foto!) e descritas por Moore (1915) como parte do seu trabalho "The Aristolochia of Pará (Brazil)". A espécie tem distribuição na América do Sul, e no Brasil ocorre nas regiões Norte: Acre, Amazonas e Pará; Centro-Oeste; Mato Grosso do Sul e Sudeste: Minas Gerais e São Paulo (Flora do Brasil 2020, em construção).

Hoehne (1927) descreveu Aristolochia dubia, também baseada em material do Rev. Milles Moss s.n., coletado em setembro de 1914 e depositado no Herbário do Museu Goeldi (MG!). Essa espécie foi proposta como sinônimo de $A$. mossii por Ahumada (1977) e confirmada como 
sinônimo heterotípico por Freitas et al. (2017), com o que se concorda nesse trabalho. Pelos dados de coleta e semelhança dos espécimes, considera-se que tal material poderia até ser uma duplicata do holótipo de A. mossii depositado no BM.

Em Carajás, Aristolochia mossii é de fácil reconhecimento por ser uma trepadeira robusta sobre arbustos e árvores, com florada contendo profusão de flores de cor amarelada com manchas marrons. De acordo com a etiqueta do espécime Tyski $63 \mathrm{em}$ HCJS, tem nome popular de "cipó mil homens" e odor desagradável, essa última característica também reafirmada na etiqueta do espécime de Bastos 89 em HCJS. A espécie foi observada e fotografada recentemente na Serra Norte na margem de capão, mas não foi coletada (Fig. 2a-b).
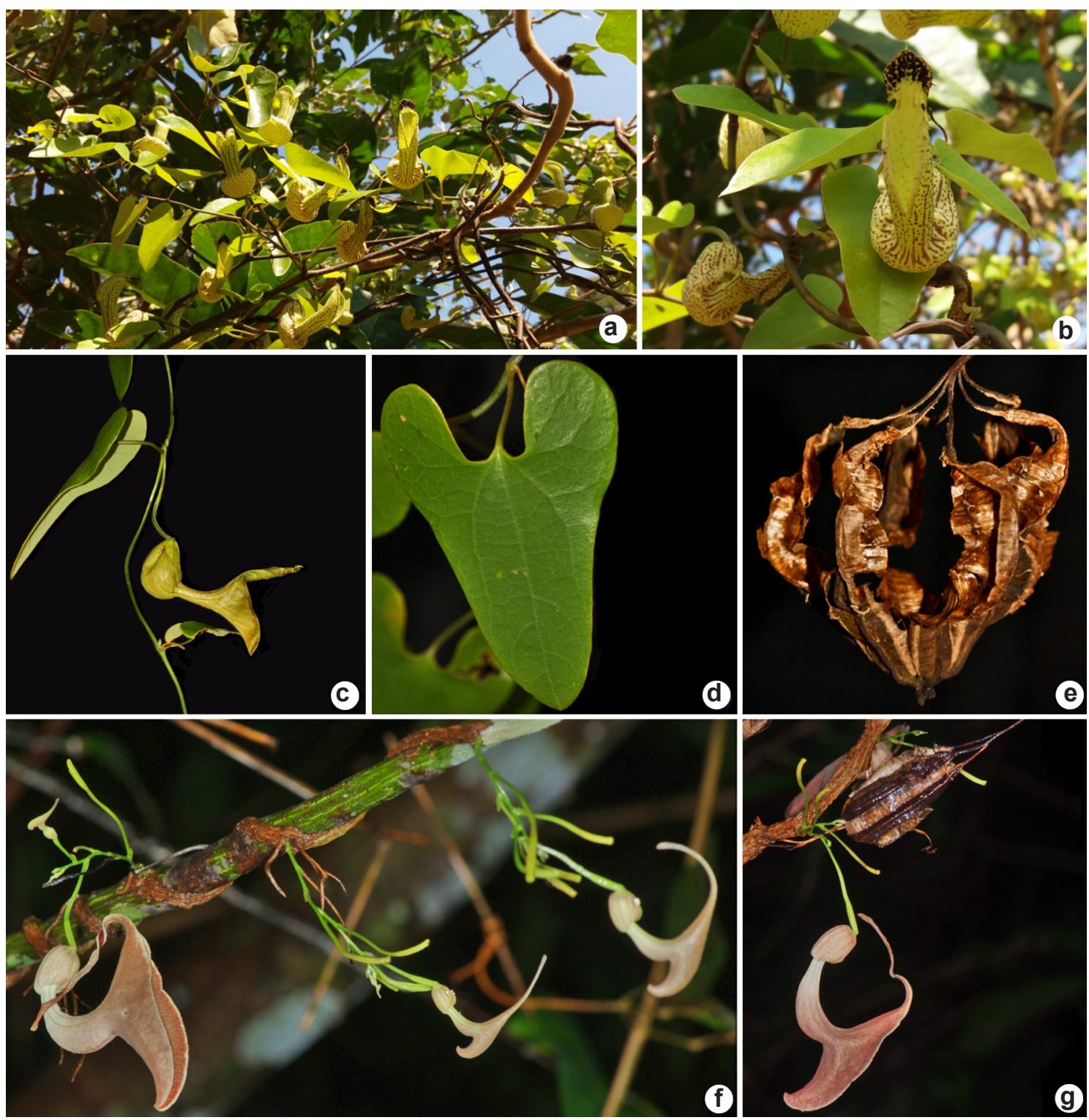

Figura 2 - a-b. Aristolochia mossii - a. hábito; b. flor em vista frontal, mostrando as fímbrias no lábio superior. c-e. Aristolochia rugosa - c. hábito; d. folha; e. cápsula deiscente. f-g. Aristolochia aff. disticha - f. hábito; g. detalhe do hábito e cápsula não deiscente. Fotos: a-b. T.C. Giannini; c-e. A. Simões; f-g. P. Viana.

Figure 2 - a-b. Aristolochia mossii - a. habit; b. flower in frontal view, showing the fimbria on upper lip. c-e. Aristolochia rugosa - c. habit; d. leaf; e. capsule dehisced. f-g. Aristolochia aff. disticha - f. habit; g. detail of habit and undehisced capsule. Photos: a-b. T.C. Giannini; c-e. A. Simões; f-g. P. Viana. 
1.3. Aristolochia rugosa Lam. Encyclopédia Methodique Botanique 1:252. 1783.

Figs. 1h-j; 2c-e

Trepadeira volúvel, perene; ramos pubérulos, súber presente; profilos intrapeciolares ausentes. Folhas com pecíolo $2-3,5 \mathrm{~cm}$ compr.; lâmina oval, 7,5-14,5 × 4,1-8 cm, papirácea, ápice agudo, base lobada, sinus 1,5-3 cm compr., face adaxial glabra, face abaxial pubérula; 6 nervuras a partir da dicotomização das nervuras principais e laterais. Flores solitárias, pedúnculo (incluindo o ovário) 2-3 cm compr., glabro. Perianto externamente, quando em botão verde-escuro quase negro, em antese com tubo inferior verde claro com nervuras castanhas e tubo superior castanho-esverdeado, pubérulo, internamente verde com tricomas púrpura; tubo inferior obovoide, ca. 1,2 cm compr.; tubo superior, 3-3,5 cm compr.; lábio inferior oval, margem revoluta, ápice agudo; lábio superior oval, internamente verde com estrias marrom, margem plana, ápice agudo. Cápsulas elipsoides, ca. $5 \times 1,4$ $\mathrm{cm}$ (fechadas), rostradas, septos fibrosos. Sementes ovais, ca. 0,4 $\times 0,4 \mathrm{~cm}$, quase planas, margem e rafe salientes.

Material examinado: Canaã dos Carajás, Serra Sul, S11D, acampamento da GEOSOL, na margem de capão, 06²3'49”'S, 50²0'56”'W, 762 m, 02.XII.2015, fl. e fr., J.R. Trindade et al.380 (MG). Serra Sul, área de floresta, solo pedregoso, $06^{\circ} 19^{\prime} 43^{\prime \prime} \mathrm{S}, 50^{\circ} 07^{\prime} 57^{\prime \prime} \mathrm{W}$ 763 m, 12.XII.2016, bot., C.A.S. Silva et al. 548 (MG). Material adicional examinado: BRASIL. PARÁ: Ourilândia do Norte, Colônia Nossos Campos, capoeira ao pé da Serra do Puma, solo argiloso com afloramentos rochosos, 24.III.2003, fr., C.S. Rosário \& E. Almeida 2268 (MG).

Aristolochia rugosa foi descrita por Lamark (1783) que refere a sua ocorrência para Guadalupe e Santo Domingo (República Dominicana). Para o Brasil a espécie é referida para as regiões Norte: Amazonas, Pará e Rondônia; Nordeste: Maranhão; Centro-Oeste: Distrito Federal, Goiás, Mato Grosso e Mato Grosso do Sul; Sudeste: Minas Gerais, Rio de Janeiro e São Paulo (BFG 2015; Flora do Brasil 2020, em construção). Em Carajás: Serra Sul: S11D.

Apesar dos caracteres vegetativos e das cores e forma das flores serem condizentes com os de A. rugosa, esta espécie é referida como portando fímbrias no perianto, característica que não foi observada nos espécimes de Carajás, que possuem tricomas de cor púrpura. Apesar dessa diferença, optamos por identificar a espécie como Aristolochia rugosa, mesmo porque, a presença e ausência de fímbrias na mesma espécie, já foi referida por Abreu (2015) ao descrever variabilidade morfológica em Aristolochia papillaris Mast., refere que os espécimes da Bahia apresentam fímbrias, enquanto Melo et al. (2013) descrevem que as plantas de Alagoas, Paraíba e Pernambuco não apresentam fímbrias.

\section{Agradecimentos}

Agradecemos ao Instituto Tecnológico Vale e ao Museu Paraense Emilio Goeldi, a estrutura e o apoio fundamentais ao desenvolvimento do projeto. Aos diversos setores da VALE, o apoio e infra-estrutura de campo. Ao ICMBio, a licença de coleta. A João Silveira, a confecção das ilustrações. A André Simões, Pedro Viana e Tereza Cristina Giannini, as fotografias que ilustram este trabalho. Aos curadores dos herbários MG, CVRD e HCJS, o acesso as coleções. Aos assessores anônimos, a leitura e sugestões apresentadas. Ao Instituto Tecnológico Vale (Convênio 01205.000250/201410) e ao CNPq (Processo 455505/2014-4), o financiamento do projeto. Ao CNPq, a bolsa Sênior a A.M. Giulietti e a CAPES, a bolsa PDI a N.F. Mota.

\section{Referências}

Abreu IS (2015) Morfologia e taxonomia da família Aristolochiaceae na Bahia. Dissertação de Mestrado. Universidade Estadual de Feira de Santana, Feira de Santana. Pp: 1-123.

APG IV (2016) An update of the Angiosperm Phylogeny Group classification for the orders and families of flowering plants: APG IV. Botanical Journal of the Linnean Society 181:1-20.

Ahumada Z (1977) Novedades sistemáticas en el género Aristolochia (Aristolochiaceae) in Sudamérica, I. Darwiniana 21: 65-80.

BFG - The Brazil Flora Group (2015) Growing knowledge: an overview of seed plant diversity in Brazil. Rodriguésia 66: 1085-1113. DOI: 10.1590/2175-7860201566411.

Barringer K (1993) New combination in North America Asarum (Aristolochiaceae). Journal of the Arnold Arboretum 64: 565-597.

Bolin JF, Maass E \& Musselman LJ (2011) A new species of Hydnora (Hydnoraceae) from southern Africa. Systematic Botany 36: 255-260.

Flora do Brasil (2020, em construção)Aristolochiaceae. In: Jardim Botânico do Rio de Janeiro. Disponível em <http://floradobrasil.jbrj.gov.br/reflora/ floradobrasil/>. Acesso em 24 janeiro 2018.

Freitas J, Lírio EJ, González F, Sarnaglia Jr VB \& Alves-Araujo A (2017) Notes on taxonomy and nomenclature of the F.C. Hoehne's names to Aristolochia (Aristolochiaceae). Phytotaxa 307: 65-74. 
González F (1990)Aristolochiaceae. In: Rangel JO, Cadena A, Correal GV, Bernal RG \& Lozano-Contreras G (eds) Flora da Colombia. Vol. 12. Universidad Nacional de Colombia, Bogotá. Pp. 1-184.

González F (1997) Hacia una filogenia de Aristolochia y sus congeneres neotropicais. Caldesia 19:115-130.

González F, Freitas J \& Lírio EJ (2014) On the typification, identity, and synonymy of Aristolochia disticha Mast. (Aristolochiaceae). Brittonia 66: 337-339. DOI 10.1007/s12228-014-9341-5.

Griffith W (1845) On the root-parasites referred by authors to Rhizantheae, and on various plants related to them. Transactions of the Linnean Society 19: 303-348.

Hoehne FC (1927) Monografia ilustrada das Aristolochiaceas brasileiras. Memórias do Instituto Osvaldo Cruz 20: 67-175.

Hoehne FC (1942) Aristolochiaceas. Flora Brasílica. Vol. 15. Instituto de Botânica, São Paulo. Pp. 1-141.

Huber H (1993) Aristolochiaceae. In: Kubitzki K, Rohwer JG \& Bittrich V (eds.) The families and genera of vascular plants. Springer, Berlin. Pp. 129-137.

Kelly LM \& González F (2003) Phylogenetic relationships in Aristolochiaceae. Systematic Botany 28: 236-249.

Lamark C (1783) Encyclopédie Méthodique Botanique. Vol.1. Panakoucke Libraire, Paris. Pp. 1-344.

Machado RF \& Queiroz LP (2012) A new species of Prosopanthe (Hydnoraceae) from northeastern Brazil. Phytotaxa 75: 58-64.

Massoni J, Forest F \& Sauquet H (2014) Increased sampling of both genes and taxa improves resolution of phylogenetic relationships within Magnoliidae, a large and early-diverging clade of angiosperms. Molecular Phylogenetics and Evolution 70: 84-93.

Masters MT (1875) Aristolochiaceae. In: Martius CFP, Eichler AG \& Urban I (eds.) Flora Brasiliensis. Lipsiae. Vol. 4, pars 2, pp. 77-114.

Melo A, Araujo AAM \& Alves M (2013) Flora da Usina São José, Igarassu, Pernambuco: Aristolochiaceae e Piperaceae. Rodriguésia 64: 543-553.

Moore S (1915) The Aristolochia of Pará (Brazil). Journal of Botany 53: 1-8.

Naumann J, Salomo K, Der JP, Wafula EK, Bolin JF, Maass E, Frenzke L, Samain MS, Neinhuis C, de Pamphilis CW \& Wanke S (2013) Singlecopy nuclear genes place haustorial Hydnoraceae within Piperales and reveal a Cretaceous origin of multiple parasitic angiosperm lineages. PLoS ONE 8: e79204.

Nickrent DL, Blarer A, Qiu YL, Soltis DE, Soltis PS \& Zanis MJ (2002) Molecular data place Hydnoraceae with Aristolochiaceae. American Journal of Botany 89: 1809-1817.

Neinhuis C, Wanke S, Hilu KW, Müller K \& Borsch $\mathrm{T}$ (2005) Phylogeny of Aristolochiaceae based on parsimony, likelihood, and Bayesian analyses of $\operatorname{trn} \mathrm{L}-\operatorname{trn} \mathrm{F}$ sequences. Plant Systematics and Evolution 250: 7-26.

Ohi-Toma T, Sugawara T, Murata H, Wanke S, Neinhuis C \& Murata J (2006) Molecular phylogeny of Aristolochia sensu lato (Aristolochiaceae) based on sequences of $r b c L$, matK, and phyA genes, with special reference to differentiation of chromosome numbers. Systematic Botany 31: 481-492.

Pfeifer HW (1966) Revision of the North and Central American hexandrous species of Aristolochia (Aristolochiaceae). Annals of the Missouri Botanical Garden 53: 115-196.

Qiu YL, Dombrovska O, Lee J, Li L, Whitlock BA, Bernasconi-Quadroni F, Rest JS, Davis CC, Borsch T, Hilu KW, Renner SS, Soltis DE, Soltis PS, Zanis MJ, Cannone JJ, Gutell RR, Powell M, Savolainen V, Chatrou LW \& Chase MW (2005) Phylogenetic analysis of basal angiosperms based on nine plastid mitochondrial and nuclear genes. International Journal of Plant Sciences 166: 815-842.

Rulik B, Wanke S, Nuss M \& Neinhuis C (2008) Pollination of Aristolochia pallida Willd. (Aristolochiaceae) in the Mediterranean. Flora 203: 175-184.

Sakai S (2002) Aristolochia spp. (Aristolochiaceae) pollinated by flies breeding on decomposing flowers in Panama. American Journal of Botany 89: 527-534.

Shaiju PN \& Omarakumari N (2010) Floral morphology and systematics of the genus Thottea Rottb. (Aristolochiaceae) from the Western Ghats, India. Plant Systematic and Evolution 288:213-225.

Stevens PF (2001, onwards) Angiosperm Phylogeny Website. Version 14, July 2017 [and more or less continuously updated since]. Disponível em $<$ http:// www.mobot.org/MOBOT/research/APweb/>. Acesso em 5 fevereiro 2018.

Lista de exsicatas

Bastos JAA 89 (1.2). Rosa NA 4532 (1.2). Rosario CS 2268 (1.3). Secco R 566 (1.1). Silva CAS 548 (1.3). Silva MN 252 (1.1). Trindade JR 380 (1.3). Tyski L 63 (1.2). Viana PL 5667 (1.1). 
